\section{Condition of Freshly Burnt Gases}

IN his interesting article on "The Condition of Freshly Burnt Gases", Dr. A. G. Gaydon gives very clear expression to his view that during the com. bustion of dry carbon monoxide mixtures the freshly formed carbon dioxide is charged with a large excess of vibratory energy which is only very slowly partitioned; but if the carbon monoxide mixtures are moist, or a little hydrogen is added to them, partitioning of the excess vibratory energy in the carbon dioxide takes place rapidly because of the powerful deactivating influence of water vapour. Experiment, however, seems to indicate that this view is untenable.

It has been found that the rate of emission of infrared radiation measured after (even immediately after) the combustion of reasonably dry carbon monoxideair mixtures is not greater than that measured after the combustion of similar mixtures in which a little of the carbon monoxide is replaced by hydrogen ${ }^{2}$. Indeed it is rather less, because water vapour radiates more powerfully than carbon dioxide. At all times after combustion, the rate of emission of radiation from carbon dioxide, like that from water vapour, would appear to be dominated by flame gas temperature (mean molecular translational energy) and influenced not at all by its previous combustion history.

The question as to whether or not normal gases would luminesce if externally heated to the temperatures usually attained in flames and explosions is one of long standing, and Dr. Gaydon redirects attention to it in his article. He suggests that gases like nitrogen, oxygen and carbon monoxide would not luminesce, and probably there will be general agreement with this view. He thinks, however, that carbon dioxide would luminesce after the fashion of carbon monoxide flame gases on account of the recombination which is continuously taking place after dissociation.

But there is, I think, much evidence for the contrary view, and some of this has been referred to by me in a previous communication ${ }^{3}$. Even more convincing evidence seems to be provided by the flame photographs of carbon monoxide - oxygen explosions taken by Bone and Frazer ${ }^{4}$. The photographs show that when these mixtures are ignited by means of an ordinary spark, the usual luminosity is displayed by the resulting flame gases (for example, photograph No. 19). When, however, they are ignited by means of a very powerful spark, a considerable volume of the gases formed under its influence is dark (for example, photographs Nos. 22 and 23), and this in spite of the fact that an enormous amount of dissociation and recombination must be taking place in them, for their temperature is of the order of $3,000^{\circ} \mathrm{C}$.

It is not without interest to observe that the longtube explosion photographs of Bone and Frazer suggest that flame gases also tend to approach the condition of normal hot gases just immediately after detonation has been set up (see, for example, photographs Nos. 5, 17, 22 and 32).

While Dr. Gaydon's article makes it clear that explanations differ, it is becoming increasingly recognized that the experimental evidence for the existence of a long-lived latent energy in carbon monoxide flame gases is irrefutable. The experimental evidence that it exists in hydrogen and hydrocarbon flame gases is, I think, equally irrefutable ${ }^{8}$

Engineering Department,

W. T. David.

The University,

Leeds.

Nov. 2.

1 NATURE, 150, 481 (1942).

${ }^{2}$ Phil. Mag., 15, 177 (1933), Figs. 2 and 4.

${ }^{3}$ NATURE, 150, 291 (1942).

- Phil. Trans. Roy. Soc., 228, 197 (1929).

${ }^{5}$ Phil. Trans. Roy. Soe., 230, 363 (1931).

- Nature, 150, 521 (1942), and Phil. Mag., 22, 513 (1936).

Prof. David refers to his experiments with Parkinson on the rate of emission of radiation from explosions. In this paper I find no mention of any drying process for the gases, or of any attempt to remove adsorbed moisture from the explosion vessel. I therefore assume that the gases were far from dry, and these experiments can scarcely be compared with those of Garner and colleagues to which I referred. They appear to me to support my statement that the concept of vibrationally activated molecules could not explain afterburning or latent energy of long duration in hydrogen-rich fuels. Also I may perhaps be permitted to quote Prof. David's own words relating to some earlier work on coal-gas-air explosions", that the "rate of emission of radiation is a maximum about $1 / 40$ sec. before the attainment of maximum temperature". This effect is also very well shown in the curves of David and Parkinson to which Prof. David refers, Curve A in Fig. 2 showing a difference of about 0.03 sec. and Curve B in Fig. 3 of more than 0.05 sec., although for mixtures rich in hydrogen the effect is not observed.

I have shown ${ }^{2}$ that the radiative life of the asymmetrical vibration for carbon dioxide is of the order 0.01 sec. and that even in absolutely dry gases the time for equipartition of vibrational energy will be, at most, a few tenths of a second, and very considerably less in the presence of moisture. It is doubtful whether a bolometer of 0.02 sec. period (as used by David and Parkinson) would be adequate for work on moist gases.

With regard to the luminosity of hot gases, I still retain an open mind. I have made it clear in my article and book that the radiation from a carbon monoxide flame is mainly due to chemical causes, and the failure to record appreciable light from hot gases in the neighbourhood of a powerful spark using a very short exposure time proves nothing, except that there is less chemical action taking place. This is probably the result of the pressure wave reducing the time-lag in the equipartition of vibrational energy, and thereby the amount of abnormal dissociation.

I do not feel qualified to express an opinion as to the existence of long-lived latent energy in hydrogen and hydrocarbon fuels. I have already pointed out that there is much apparently contradictory experimental evidence.

\section{Imperial College of Science and Technology, London, S.W.7.}

${ }^{1}$ Phil. Trans. Roy. Soc, A, 211, 375 (1911).

"Spectroscopy and Combustion Theory", p. 121. (London : Chapman and Hall, 1842.) 